\title{
PRODUÇÃO FAMILIAR RURAL E DESIGUALDADE DE RENDA NA AMAZÔNIA: UM ESTUDO DO PROJETO RECA, EM PORTO VELHO, RONDÔNIA
}

\begin{abstract}
Resumo
Este artigo analisa o desempenho econômico da produção familiar obtido pelos produtores familiar rurais do projeto Reflorestamento Econômico Consorciado e Adensado - RECA, em Porto Velho - RO. Especificamente visa contribuir com o entendimento da economia da produção familiar rural na Amazônia e com a concentração de renda na região, buscando compreender como a renda evoluiu e foi distribuída ao longo de dez anos. Para isso utilizamos indicadores de desempenho econômico e de medidas de concentração de renda. Pelos dados encontrados constatamos que ocorreu uma diminuição no número de pobres e uma distribuição de renda mais equitativa no RECA quando comparado com outros sistemas produtivos praticados na região.
\end{abstract}

Raimundo Claudio Gomes Maciel ${ }^{1}$

Maria Jeigiane Portela da Silva ${ }^{2}$ Janio Nascimento de Aquino ${ }^{3}$ Marta Nogueira de Azevedo ${ }^{4}$

Pedro Gilberto Cavalcante Filho ${ }^{5}$ Elyson Ferreira de Souza ${ }^{6}$

Palavras chaves: Produção familiar rural. Desempenho econômico. Desigualdade de renda. Amazônia. Projeto RECA.

\section{Abstract}

This paper examines the economic performance of family farming rural households obtained by producers of the project consortium and reforestation and economic Compacted - RECA in Porto Velho - RO, Brazil. Specifically aims to contribute to the understanding of the economy of rural household production in the Amazon and the concentration of wealth in the region, seeking to understand how income was evolved and spread out over ten years. For that use economic performance indicators and measures of income concentration. By findings found that there was a decrease in the number of poor and a more equitable distribution of income when compared to other production systems practiced in the region.

Keywords: Rural family production. Economic performance and income e inequality. Amazon Region. Project RECA.

\footnotetext{
${ }^{1}$ Doutor em Economia Aplica pela Universidade Estadual de Campinas (UNICAMP)

Professor do Programa de Pós-Graduação em Mestrado em Desenvolvimento Regional da Universidade Federal do Acre (PPG-MDR/UFAC)

2 Mestre em Desenvolvimento Regional da Universidade Federal do Acre. Graduação em Ciências Econômicas pela Universidade Federal do Acre (2003). Especialista em Gestão de Projetos pela Fundação Getúlio Vargas e em Agricultura Familiar Camponesa e Educação do Campo pela Universidade Federal do Pará

${ }^{3}$ Graduado em Agronomia pela Universidade Federal do Acre (UFAC). Consultor - Programas das Nações Unidas para o Desenvolvimento - PNUD no Brasil.

${ }^{4}$ Mestre em Desenvolvimento Regional pela Universidade Federal do Acre (UFAC). Gestora de Políticas Públicas da Secretaria Estadual de Meio Ambiente do Acre (SEMA).

${ }^{5}$ Acadêmico do Curso de Ciências Econômicas pela Universidade Federal do Acre (UFAC).

${ }^{6}$ Doutor em Desenvolvimento Econômico pela Universidade Estadual de Campinas (UNICAMP).
}

Revista de Estudos Sociais | Ano 2017, N. 39, V. 20, Pag. 3 
Q - Agricultural and Natural Resource Economics; Environmental and Ecological Economics

Q15 - Land Ownership and Tenure; Land reform; Land use; Irrigation

\section{INTRODUÇÃO}

Um dos grandes desafios do mundo moderno é conservar o meio ambiente por meio da utilização racional dos recursos naturais, com vistas a garantir sustentável geração de renda e melhor qualidade de vida a todos, principalmente àqueles que habitam e exploram ecossistemas tropicais como os da Amazônia. Essa preocupação é incorporada no que se convencionou chamar de desenvolvimento sustentável, conceituado pela Comissão das Nações Unidas para o Meio Ambiente no relatório Nosso Futuro Comum, como aquele capaz de atender às necessidades da geração atual sem comprometer 0 potencial de suprir as necessidades das gerações futuras (Nosso Futuro Comum, 1991). Desde então, têm surgido várias interpretações para o desenvolvimento, meio ambiente e a gestão dos recursos naturais.

Silva e Mendes (2005, p. 37) conceituam desenvolvimento sustentável "[...] como um processo de transformação que ocorre de forma harmoniosa nas dimensões espacial, social, ambiental, cultural e econômico a partir do individual para o global". Para esses autores, o desenvolvimento sustentável acontecerá se as dimensões sociais, culturais, econômicas, ambientais e institucionais avançarem, atendendo as restrições existentes de forma harmoniosa.

Já o conceito de meio ambiente não é "neutro", é uma construção histórica e social que adquire sentidos diferentes quando mencionada por agentes do campo ambiental e por agentes da produção familiar rural que vêem os recursos naturais como meio de reprodução. Para Gudynas (2003, p. 29),

La categoria de Naturaleza es uma creación social, distinta em cada momento histórico, cambiante de acuerdo a cómo los hombres se vicunlan con su entorno.[...], en América Latina, han sido los humanos tambiém los autores "ecológicos" de la Naturaleza em muchas áreas, al haber intervenido em la conformación de los ecosistemas, seleccionado variedades de plantas y animales y moldeado el paisaje.

A discussão sobre desenvolvimento sustentável da produção familiar rural, geralmente, despreza a perspectiva microeconômica de análise da questão. Os críticos dessa dimensão analítica alegam que se trata de uma abordagem inadequada ao entendimento de questões que envolvem unidades produtoras com modo particular de produção não capitalista. E, como modo particular de produção, o processo de tomada de decisão requer que se entenda a unidade de produção familiar como um sistema aberto que mantém relações com o meio ambiente físico, socioeconômico e cultural, e que subtraiam deste conjunto, incluindo a unidade de produção, os elementos que determinam o funcionamento do sistema. Dessa forma, o meio ambiente constitui um conjunto de fatores, elementos, variáveis ou fenômenos externos ao sistema, que influencia ou determina fortemente, com maior ou menor intensidade, as decisões e ações dos agricultores.

Revista de Estudos Sociais | Ano 2017, N. 39, V. 20, Pag. 4 
Tal compreensão é importante para se entender que a forma como as famílias se relacionam com a natureza visam a sua reprodução. Neste processo de apropriação e convivência com a natureza estabelecem relações que muitas vezes se tornam místicas e desenvolvem saberes que respeitam o tempo de produção e desenvolvimento das culturas. "[...] quando não se trabalha a terra adequadamente, não só se põe em risco a própria família, mas a comunidade $[\ldots]^{7}$.

Os resultados econômicos obtidos pelos produtores familiares rurais são essenciais para fortalecer as estratégias de desenvolvimento. Mas não se trata apenas de buscar aumento de produtividade a qualquer custo, porque isso pode ocasionar, em longo prazo, diminuição de renda, dependência crescente de fatores externos e danos ambientais que podem se traduzir em perdas econômicas no curto prazo.

Perdas estas que a longo prazo podem levá-los ao estado de pobreza, que segundo Rocha (2000), pode ser entendida como uma situação de carência de condições para satisfazer as necessidades básicas, capazes de permitir ao indivíduo ou a sua família recursos para supri-las. Buscando estabelecer critérios de aferição que permitam estipular a magnitude das necessidades básicas, muitos estudiosos passaram a utilizar a renda como variável para definir a condição social de um indivíduo, região, cidade, etc.

Considera-se que, em uma sociedade capitalista, a satisfação das necessidades individuais passa, fundamentalmente, pelo acesso aos recursos monetários, que permitem o pagamento pelo direito de uso ou consumo de qualquer mercadoria. Assim, o acesso à renda constitui-se em fator decisivo que garante ao indivíduo bens e serviços e, com isso, faculta-lhe a sua reprodução social. Partindo de premissas semelhantes a essa, os estudiosos da pobreza fazem amplo uso dos indicadores de renda para medir as condições dos membros de uma sociedade em satisfazer suas necessidades básicas e, a partir daí, apontar as discrepâncias no acesso aos recursos que existem entre indivíduos, grupos ou classes. Isso significa, em síntese, revelar o grau de desigualdade que existe em uma determinada formação social com base na análise da distribuição dos rendimentos auferidos pelas pessoas que a compõem (Schneider e Fialho, 2000).

Desta forma, discutir a concentração de renda em comunidades rurais constitui um elemento importante para compreensão de seus processos de desenvolvimento e para formulação de estratégias que visem minimizar tais desigualdades.

\section{METODOLOGIA}

\subsection{Caracterização do Projeto Reca}

O local de estudo situa-se na Ponta-do-Abuña (constituída pelos distritos de Nova Califórnia, Extrema, Vista Alegre do Abunã e Fortaleza do Abunã), extremo Oeste de Rondônia. Ao norte faz fronteira com o Estado do Acre, a leste com o Amazonas e ao sul com a Bolívia, situando-se entre os rios Abuña e Aquiri,

${ }^{7}$ Tradução livre. [...] Cuando no se trabaja adecuadamente la tierra, no solo se pone em riesgo a la propia família, sino a la comuna, [...]" (Gudynas, 2003, p. :27).

Revista de Estudos Sociais | Ano 2017, N. 39, V. 20, Pag. 5 
na Amazônia Ocidental. Sendo que Projeto RECA está localizado no distrito de Nova Califórnia.

Em 1980, o INCRA identificou e dividiu a área, chamando-a de Projeto de Assentamento Alto Madeira. Em 1982, "cortou" os lotes, abriu os primeiros picadões e estradas vicinais e foi fazendo a entrega. Em 1984, destinou 800 hectares para a instalação do núcleo urbano nas proximidades do posto de combustível e de um "restaurante", às margens da BR-364, concluindo essa etapa em 1985. Após esse período, o poder público ausentou-se do local. As primeiras famílias imigrantes sócias do RECA chegaram em Nova Califórnia na primeira metade da década dos anos 1980. Muitos deles já haviam passado por Rondônia ou outras regiões em busca de uma terra para viver.

Em setembro de 1984 foi criada a Cooperativa Mista Agropecuária do Alto Abuña (Coopermab). Apesar do apoio inicial e de ser ponto de encontro dos produtores, não prosperou mais que dois anos, visto a falta de experiência em organização comunitária dos cooperados e da diretoria.

Aqueles que resistiram resolveram unir-se. Foi assim que, em 1987, criaram a Associação dos Produtores Rurais da Linha 5 e dos Pioneiros. Com o apoio da Igreja Católica, a organização dos produtores foi ganhando força. Essas associações conseguiram auxílio do Governo do Acre e da Igreja Católica (por intermédio da Cáritas Brasileira), obtendo alguns benefícios, como: peladeira de arroz, carroça, matrizes de gado bovino, animais de tração e conservação de ramais.

A ideia de cultivar lavouras perenes foi trazida de experiência anterior dos produtores fundadores da associação com trabalho realizado na agricultura, como meeiro, arrendatário e diarista nas lavouras de cacau e café em Rondônia. Contudo, essas culturas já familiares esbarraram em problemas: o cacau foi atacado pela vassoura de bruxa e o café tropeçou na dificuldade de comercialização. Daí surgiu à necessidade de algo que oferecesse maior rendimento econômico e que se adaptasse a região.

Em 1988, reunidos, os produtores da Associação da Linha 5 e Pioneiros, com intermédio da Paróquia São José de Nova Califórnia, Diocese de Rio Branco e CPT, elaboraram um pré-projeto de apoio à produção, no qual expunham suas intenções. O projeto denominou-se "Reflorestamento Econômico Consorciado e Adensado - RECA". No mesmo ano apresentaram o projeto Reca ao Banco do Brasil, Banco do Estado do Acre - Banacre e Banco do Estado de Rondônia Beron, mas não foram financiados por essas instituições. Encaminharam então ao Centro de Estatística Religiosa e Investigações Sociais - Ceris, no Rio de Janeiro, que depois de discutido e reformulado por diversas vezes, foi endereçado à Organização Católica Holandesa de Cooperação para o Desenvolvimento - CEBEMO, na Holanda, a qual aprovou o projeto. No início do ano de 1989 os recursos para implementá-lo começaram a ser liberados, oportunidade em que foi fundada a Associação dos Pequenos Agrossilvicultores do Projeto de Reflorestamento Econômico Consorciado e Adensado, com 80 sócios, para efetuar seu gerenciamento. Assim iniciou a história do projeto RECA.

Hoje a vila Nova Califórnia é um distrito de Porto Velho-RO, com uma distância aproximada de $480 \mathrm{~km}$ da capital rondoniense, possui uma área de aproximadamente $10.000 / \mathrm{km}^{2}$, população com cerca de 3 mil habitantes, dos quais aproximadamente $55 \%$ residem na zona rural e $45 \%$ na zona urbana da

Revista de Estudos Sociais | Ano 2017, N. 39, V. 20, Pag. 6 
capital rondoniense. E o projeto RECA é formado por 10 grupos de diferentes tamanhos e inclui um total de 240 famílias. Conta com uma estrutura de beneficiamento e comercialização que garante aos agrossilvicultores a verticalização da cadeia produtiva e a gestão comunitária da produção.

\subsection{Definição da Amostra e Indicadores de Análise}

Aplicou-se um total de 30 questionários nas unidades produtivas pertencentes aos dez grupos de produtores que formam a associação RECA (BR-364, Baixa Verde, Cascalho, Linha 5-1, Linha 5 2-3, linha 12, Mendes Júnior, Pioneiros I, Pioneiros II e Pioneiros III). Junto com o questionário também foi aplicado um roteiro de entrevista, no qual coletamos informações sobre o processo de chegada e histórico da região. Além destes instrumentos, utilizouse a comunicação pessoal para obtenção de outras informações relevantes.

Para fazer a avaliação socioeconômica da produção familiar rural Reca trabalha-se com uma metodologia específica a este tipo de produção, que será apresentada posteriormente e está sendo consolidada nos últimos quinze anos pelo projeto de pesquisa Análise Socioeconômica de Sistemas de Produção Familiar Rural no Estado do Acre, denominado ASPF8, desenvolvido pelo Departamento de Economia da Universidade Federal do Acre (UFAC), desde 1996, capitaneado atualmente pelo Centro de Ciências Jurídicas e Sociais Aplicadas (CCJSA).

Assim, para a consecução dos objetivos da pesquisa, buscou-se trabalhar a metodologia a partir de indicadores e índices socioeconômicos que, por um lado, levem em consideração as peculiaridades da região de estudo e, por outro, sirvam como parâmetros para relacionar as diversas regiões e determinadas formas de organização produtiva dos produtos comercializados, comparando-as entre si e indicando as prioridades de atuação para um efetivo desenvolvimento socioeconômico sustentável. Portanto, segue uma descrição sucinta da metodologia de pesquisa.

O levantamento dos dados realizou-se por amostragem seguindo 0 critério de que a residência do agrossilvicultor no lote seja superior a dois anos. A amostra ${ }^{9}$ é definida a partir de três etapas:

1. Estratificação da área de acordo com nível de desenvolvimento (alto, médio ou baixo), tendo como referência os critérios relativos aos volumes de produção, facilidade e qualidade de acesso, disponibilidade de infraestrutura e assistência técnica, além do grau de organização comunitária;

2. Sorteio de metade dos conglomerados das áreas de estudo - ramais, no caso de áreas agrícolas, e, os seringais, no caso de áreas extrativistas -, tendo em vista a representatividade dentro de cada estrato definido;

3. Por fim, dentro de cada conglomerado sorteado, foi realizada uma amostragem aleatória simples, sorteando-se 10\% das unidades de produção, que seriam o objeto de estudo.

Utiliza-se como referência para o levantamento das informações, o calendário agrícola da região, definido conjuntamente com as próprias comunidades estudadas, que compreende o período de maio do ano referência

\footnotetext{
${ }^{8}$ Para maiores informações, inclusive sobre publicações, visite: http://aspf.wordpress.com/.

${ }^{9}$ A partir da amostragem do Projeto ASPF já foram desenvolvidos diversos trabalhos, como Maciel et. al (2014), Loiola e Maciel (2015), Souza (2008) etc.
}

Revista de Estudos Sociais | Ano 2017, N. 39, V. 20, Pag. 7 
a abril do ano seguinte, e engloba o conjunto de atividades econômicas produtivas das famílias. Na presente avaliação considerou-se os anos agrícolas de 1996/1997 e 2005/2006, uma vez que foram os últimos levantamentos realizados no referido projeto de assentamento.

Trabalha-se com medidas de resultado econômico, que são indicadores/índices que, dados os custos de produção, permitem medir o desempenho econômico do sistema de produção. Os principais indicadores econômicos são sucintamente descritos a seguir:

1) Resultado Bruto

1.1. Renda Bruta (RB) - indicador de escala de produção

$R B=Q_{m} \cdot P_{p}$

sendo:

$R B=$ renda bruta

$Q_{m}=Q_{v}+Q_{e}$

$Q_{m}=$ quantidade do produto destinada ao mercado

$Q_{v}=$ quantidade do produto vendida

$Q_{e}=$ quantidade do produto do exercício em estoque

$P_{p}=$ preço unitário ao produtor

2) Resultados Líquidos

2.1. Renda Líquida $(R L)$ - excedente apropriado

$R L=R B-D E$

sendo:

$R L=$ renda líquida

$R B=$ renda bruta

$D E=$ despesas efetivas

2.2. Lucro da Exploração (LE) - possibilidade de acumulação

$L E=R B-C T$

sendo:

$R B=$ renda bruta

$C T=$ custos totais

2.3.Margem Bruta Familiar (MBF) - valor monetário disponível para a família

$M B F=R B-\left(C V-C_{f t f}\right)$

sendo:

$R B=$ renda bruta

$C V=$ custos variáveis

$C_{f t f}=$ custo real da força de trabalho familiar

2.4. Nível de Vida (NV) - indicador monetário do padrão de vida

$N V=\left(M B F+A C+C_{j i c c}\right)-A A$

sendo:

$C_{j i c c}=$ juros imputados ao capital circulante;

$A A=$ amortizações anuais de empréstimos.

Dividido nas seguintes classes:

Revista de Estudos Sociais | Ano 2017, N. 39, V. 20, Pag. 8 
A - NV > 4 Salários Mínimos (SM)/mês;

B - $2 \mathrm{SM} / \mathrm{mês}<\mathrm{NV}<4 \mathrm{SM} / \mathrm{mês}$;

C (a - alto) - $1 \mathrm{SM} / \mathrm{mês}<\mathrm{NV}<2 \mathrm{SM} / \mathrm{mês}$;

C (b - baixo) - 1/2 SM/mês < NV < $1 \mathrm{SM} /$ mês;

D - $1 / 2 \mathrm{SM} / \mathrm{mês}<\mathrm{NV}<1 / 4 \mathrm{SM} / \mathrm{mês}$;

$\mathrm{E}-\mathrm{NV}<1 / 4 \mathrm{SM} / \mathrm{mês}$;

3) Medidas de Relação

3.1. Índice de Eficiência Econômica (IEE) - indicador de benefício/custo

$I E E=\frac{R B}{C T}$

sendo:

$I E E>1$, a situação é de lucro

$I E E<1$, a situação é de prejuízo

$I E E=1$, a situação é de equilíbrio

3.2.MBF/Qh/d - índice de remuneração da mão de obra familiar

Sendo:

$M B F=$ Margem Bruta Familiar

$Q h / d=$ quantidade de força de trabalho familiar utilizada no ciclo produtivo da linha de exploração

3.3. Termo de Intercâmbio (TI) - índice de apropriação da RB pelo mercado.

$T I=\frac{V_{b c c}}{R B}$

sendo:

$T I=$ Termo de Intercâmbio

$V_{b c c}=$ valor dos bens de consumo comprados

$R B=$ renda bruta total

4) Indicadores de Desigualdade de Renda

4.1. Índice de Gini

Utilizou-se, no presente trabalho, o Índice de Gini que é um parâmetro internacional usado para medir a desigualdade de distribuição de renda entre os países. Varia entre 0 e 1, sendo que quanto mais próximo do zero menor é a desigualdade de renda num país, ou seja, melhor a distribuição de renda. Quanto mais próximo do um, maior a concentração de renda num país.

Conforme Teixeira (2011), geometricamente o Índice de Gini pode ser definido pela seguinte formula:

$$
G=\left|1-\sum_{k=1}^{k=n-1}\left(X_{k+1}-X_{k}\right)\left(Y_{k+1}+Y_{k}\right)\right|
$$

sendo,

$\mathrm{G}=$ coeficiente de Gini

$X=$ proporção acumulada da variável "população"

$\mathrm{Y}=$ proporção acumulada da variável "rendimento"

\subsection{Razão $10 \%+$ / 50\%- ou Razão de Kuznets}

Revista de Estudos Sociais | Ano 2017, N. 39, V. 20, Pag. 9 
Conforme Teixeira (2011), a Razão de Kuznets é uma forma de mensurar uma comparação entre as famílias mais ricas relativamente aos mais pobres. Assim, quanto maior for essa razão maior será a distância entre ricos e pobres.

\section{5) Linhas de Indigência (miseráveis) e Pobreza}

De acordo com Campos e Campos (2008), a linha de indigência diz respeito à renda mínima necessária para adquirir uma cesta de alimentos com quantidades mínimas recomendadas. A linha de pobreza é superior ao da indigência, incorporando valores, além da cesta de alimentos, relativos a despesas não alimentares, como vestuário, moradia, transporte etc. No Brasil, calcula-se a linha de pobreza com base do salário mínimo (SM) vigente, situando-se abaixo de meio $\mathrm{SM} / \mathrm{mensal}$, enquanto que são considerados indigentes aquelas famílias que ganham menos de $1 / 4$ do SM/mês.

\section{6) Atualização Monetária}

Para realizar a atualização de preços, utilizou-se o Índice Nacional de Preços ao Consumidor (INPC), elaborado pelo Instituto Brasileiro de Geografia e Estatística (IBGE). Assim, foram coletados os valores correntes (em reais) nos períodos de 1996/1997 e 2005/2006, atualizando os valores até outubro de 2016.

\section{RESULTADOS E DISCUSSÕES}

\subsection{Composição da Renda no Projeto Reca}

A composição da renda das famílias do projeto RECA é originária de atividades ligadas aos sistemas agroflorestais ${ }^{10}(38,73 \%)$, criações $(33,27)$ agricultura (28,00\%), conforme Tabela 1.

Apesar da variedade de produtos e criações que colaboram para a composição da renda das famílias do RECA, aquelas que mais contribuíram em 2006, conforme Tabela 1, foram: semente de pupunha, com 13,62\% da renda das famílias; Cupuaçu com $8,05 \%$, criação de bois com $27,68 \%$, café com $7,51 \%$ e pupunha palmito com 5,08\%.

\footnotetext{
${ }^{10} \mathrm{Na}$ Amazônia, os sistemas agroflorestais (SAFs) representam uma das formas de uso da terra mais adequadas às condições edafoclimáticas da região, embora existam poucos estudos sobre a sustentabilidade desses sistemas em longo prazo. Por promoverem uma produção de biomassa aérea e subterrânea e cobertura do solo maiores que outros agrossistemas, os SAFs favorecem o acúmulo de carbono no sistema e a conservação da fertilidade do solo, através de uma ciclagem mais eficiente de nutrientes e a redução das perdas por lixiviação e erosão. Os SAFs são também mais apropriados às condições socioeconômicas dos produtores familiares locais, pois permitem uma produção intensiva em áreas pequenas durante muitos anos e o uso de práticas simples de manejo. O Projeto Reflorestamento Econômico Consorciado e Adensado (RECA) é uma das experiências pioneiras de SAFs na Amazônia com bons resultados sociais e econômicos. Nos anos de 1988 e 1989, os produtores implantaram os SAFs baseados no consórcio de três espécies nativas: o cupuaçu (Theobroma grandiflorum), a pupunha (Bactris gasipaes) e a castanha-do-Brasil (Bertholletia excelsa).
}

Revista de Estudos Sociais | Ano 2017, N. 39, V. 20, Pag. 10 
A Tabela 1 acentua algumas mudanças ocorridas no período. Mesmo os produtos oriundos dos SAFs tendo maior participação na composição da renda, representando $38,73 \%$, este teve uma redução de participação em relação a 1996 no valor de $34,18 \%$. No entanto, a pupunha para palmito cresceu $4092,91 \%$, fato explicado pelo início do processamento do palmito de pupunha pela agroindústria da associação e o produto apresentar preços favoráveis ( $R$ \$ $5 / \mathrm{kg}$ ao produtor), além do mercado consumidor em expansão. Já o cupuaçu, considerado como um dos principais produtos do SAFs do RECA decresceu $54,60 \%$. Uma das razões pode ser o baixo preço pago pelo produto (cerca de $\mathrm{R} \$ 0,60 / \mathrm{kg}$ ) e os custos de produção elevados para esta cultura, ocasionados pelo ataque de pragas e doenças no plantio ${ }^{11}$.

Em 1997, os produtos responsáveis pela maior geração de renda em ordem crescente foram: cupuaçu, semente de pupunha, pupunha fruto, arroz e boi. Em 2006, a ordem se alterou e outro produto entra em cena, configurando a seguinte composição: semente de pupunha, café, palmito, boi e cupuaçu.

Dessa forma, os dados apontam para um desenvolvimento calcado no investimento em culturas com maior valor de mercado. Mercados estes não ainda consolidados e sujeitos as variações de preço que podem afetar sobremaneira a renda dessas famílias. Sendo assim, a pesquisa confirma o que diz Paula et. Al. (2003), os quais apontam que o Projeto RECA enfrenta alguns desafios, especialmente no que se refere ao processamento industrial dos produtos e comercialização, seja pela instabilidade dos preços ou flutuações de um mercado consumidor ainda não consolidado, seja pela falta de infraestrutura (equipamentos e instalações produtivas) adequada e, principalmente, pela ausência de políticas públicas voltadas para esse segmento da produção familiar.

Porém, os dados da composição da renda permitem aferir também que os agrossilvicultores do projeto RECA estão se movimentando de acordo com as demandas de mercado, mantendo certa diversificação da produção inerente à racionalidade da produção familiar na busca pela reprodução da família e da unidade produtiva.

Tabela 1 - Evolução da Geração de Renda Bruta por Linha de Exploração, Vale do Acre, Sistemas Extrativista, Agrícola e Agroflorestal, 1996/1997 e 2005/2006, Acre Brasil

\begin{tabular}{lcc}
\hline & \multicolumn{2}{c}{ GERAÇÃO DE RENDA BRUTA (\%) } \\
\cline { 2 - 3 } Linha de Exploração & Projeto RECA (Sistema Agroflorestal) \\
\hline & $2005 / 2006$ & ${\text { Evolução }(\%)^{\star *}}^{\text {Criações }}$ \\
Criação de Bois & $\mathbf{3 3 , 2 7}$ & $\mathbf{3 9}$ \\
Criação de Porcos & 27,68 & 49,38 \\
Criação de Aves & 3,3 & $-9,88$ \\
& 1,25 & 68,13
\end{tabular}

\footnotetext{
${ }^{11}$ Diversas pragas e doenças afetam a produção dos SAFs, principalmente a dos frutos de cupuaçu. A brocado-cupuaçu, nome dado ao besouro da espécie Conotrachelus humeropictus (Ordem Coleóptera, Família Curculionidae), é a principal praga dos SAFs do Projeto RECA. Seu ciclo de vida conta com uma fase terrestre (adulto), uma fase no fruto (ovo e larva) e uma fase no solo (pupária). Os frutos são danificados diretamente pelas larvas da broca, através de galerias formadas na casca, na polpa, deposição de fezes e destruição das sementes. Mas também podem danificar indiretamente através da entrada, pelos orifícios, de insetos oportunistas e microorganismos que contribuem para acelerar o processo de fermentação dos frutos (Silva et al. 2002).
}

Revista de Estudos Sociais | Ano 2017, N. 39, V. 20, Pag. 11 


\begin{tabular}{|c|c|c|}
\hline Outros & 1,04 & 3,94 \\
\hline Agricultura & 28 & 62,61 \\
\hline Café & 5,22 & 65,2 \\
\hline Macaxeira & 4,18 & 994,06 \\
\hline Banana & 0,1 & -* \\
\hline Melancia & 3,21 & $-^{*}$ \\
\hline Feijão & 0,29 & $-92,44$ \\
\hline Arroz & 0,35 & $-80,96$ \\
\hline Milho & 0,54 & $-68,69$ \\
\hline Outros & 14,1 & 124,85 \\
\hline Agrofloresta & 38,73 & $-34,18$ \\
\hline Pupunha Fruto & 13,62 & $-54,6$ \\
\hline Cupuaçu & 8,05 & $-54,04$ \\
\hline Pupunha Palmito & 5,08 & 4092,91 \\
\hline Café & 7,51 & $-*$ \\
\hline Outros & 4,47 & $-60,1$ \\
\hline Extrativismo & $-*$ & $-*$ \\
\hline Castanha & $-*$ & $-*$ \\
\hline Borracha & $-*$ & $-*$ \\
\hline Madeira & $-*$ & $-*$ \\
\hline Outros & $-*$ & $-^{*}$ \\
\hline
\end{tabular}

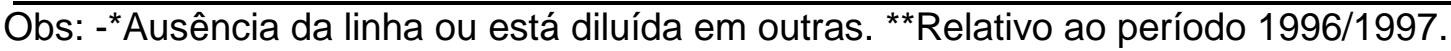
Fonte: ASPF (2014).

\subsection{Evolução do Desempenho Econômico dos Produtos no Projeto RECA}

Verifica-se, conforme Tabela 2, uma melhora significativa do desempenho econômico da produção familiar no projeto, com destaque para algumas especificidades: a pecuária está presente na quase totalidade das propriedades como componente da diversificação dos produtos; os agrossilvicultores estão investindo em atividades produtivas como apicultura, açaí, castanha nativa e coleta de sementes para a produção de óleo; o palmito de pupunha, a semente de pupunha e o café geram as maiores rendas para as famílias.

Quando se observa o índice de eficiência econômica - IEE, percebe-se uma evolução em relação a 1996, para a pupunha palmito e café de $35 \%$ e $64 \%$, respectivamente. Destaca-se que todos os produtos de origem agroflorestal (pupunha para palmito e semente, cupuaçu, café e banana) demonstraram situação de lucro em seus processos produtivos, mesmo aqueles que enfrentaram quedas no período em torno de uma década.

Tabela 2 - Evolução do desempenho econômico dos principais produtos, Vale do Acre, 1996/1997 e 2005/2006, Acre - Brasil.

\begin{tabular}{|c|c|c|c|c|c|c|c|c|c|c|}
\hline $\begin{array}{l}\text { Linha de } \\
\text { Exploração }\end{array}$ & $\begin{array}{c}\mathrm{MBF} / \mathrm{Qh} / \\
\mathrm{d}(\mathrm{R} \$)\end{array}$ & $\operatorname{EV}(\%)^{*}$ & IEE & $\operatorname{EV}(\%)^{*}$ & $\begin{array}{c}\text { Custo } \\
\text { Unitário } \\
\text { (R\$) }\end{array}$ & $\operatorname{EV}(\%)^{*}$ & $\begin{array}{c}\text { Preço } \\
(\mathrm{R} \$)\end{array}$ & $\mathrm{EV}(\%)^{*}$ & $\begin{array}{c}\text { Qtde/Ha } \\
(\mathrm{Kg})\end{array}$ & $\begin{array}{l}\text { EV } \\
(\%)^{*}\end{array}$ \\
\hline $\begin{array}{l}\text { Pupunha } \\
\text { Palmito }\end{array}$ & 159,01 & 328,67 & 2,40 & 35,34 & 0,57 & $-43,13$ & 1,36 & $-23,03$ & 342,17 & 151,59 \\
\hline Café (C) & 146,26 & 90,06 & 4,23 & 64,82 & 0,43 & $-56,38$ & 1,68 & $-29,67$ & 1366,67 & - \\
\hline Banana & 108,24 & $-79,73$ & 1,91 & $-82,24$ & 1,55 & 249,51 & 4,07 & $-14,02$ & 350,00 & $-20,45$ \\
\hline $\begin{array}{l}\text { Criação de } \\
\text { Bois }\end{array}$ & 79,98 & 34,27 & 0,90 & $-48,12$ & 406,79 & 17,52 & 475,22 & $-23,03$ & 0,24 & - \\
\hline
\end{tabular}

Revista de Estudos Sociais | Ano 2017, N. 39, V. 20, Pag. 12 


\begin{tabular}{|c|c|c|c|c|c|c|c|c|c|c|}
\hline Cupuaçu & 58,71 & $-47,31$ & 1,18 & $-86,66$ & 0,79 & 210,13 & 0,54 & $-75,78$ & 916,67 & 7,15 \\
\hline Castanha & 39,37 & 212,44 & 0,91 & $-18,31$ & 11,72 & 76,95 & 13,58 & 81,42 & - & - \\
\hline Borracha & 24,48 & 728,30 & 0,82 & 94,68 & 3,46 & 0,21 & 2,85 & 95,09 & 1,25 & 25,00 \\
\hline Feijão & 21,27 & 42,00 & 0,45 & $-47,92$ & 3,14 & 51,71 & 1,63 & $-3,50$ & 200,00 & $-33,33$ \\
\hline Arroz (C) & 16,92 & 62,12 & 0,84 & $-1,01$ & 1,60 & $-31,01$ & 1,36 & 7,76 & 500,00 & 66,67 \\
\hline Milho (C) & 13,29 & $-44,75$ & 0,49 & $-50,44$ & 0,74 & 69,84 & 0,54 & 26,78 & 400,00 & 33,33 \\
\hline $\begin{array}{l}\text { Macaxeira - } \\
\text { Farinha (S) }\end{array}$ & 12,94 & 210,84 & 0,39 & $-18,84$ & 2,77 & 0,21 & 1,09 & $-18,67$ & 1000,00 & 100,00 \\
\hline Arroz (S) & 7,37 & $-74,81$ & 0,34 & $-64,94$ & 1,68 & 0,71 & 1,36 & 7,76 & 800,00 & 26,32 \\
\hline Milho (S) & 6,09 & $-51,85$ & 0,26 & $-54,79$ & 1,18 & 56,29 & 0,54 & 26,78 & 600,00 & 12,15 \\
\hline
\end{tabular}

Obs.: *Relativo ao período 1996/1997; MBF/Qh/d - Remuneração diária da força de trabalho familiar; MBF - Margem Bruta Familiar; RB - Renda Bruta; IEE - İndice de Eficiência Econômica; C - Consorciada; S - Solteira.

Fonte: ASPF (2014).

\subsection{Desempenho Econômico das Unidades Produtivas no RECA}

$\mathrm{Na}$ Tabela 3 abaixo, verifica-se que a renda bruta gerada no RECA, representante do sistema agroflorestal, é igual a $R \$ 945,64 /$ mês. Já a renda líquida representa $R \$ 718,89 /$ mês, sendo que desta renda o produtor se apropriou, ao longo do ano agrícola, de aproximadamente $90 \%$, demonstrado pela relação $\mathrm{MBF} / \mathrm{RB}$.

O índice de eficiência econômica indica a capacidade de a unidade de produção familiar gerar valor por unidade de custo. É um indicador de benefício/custo do conjunto da unidade de produção que serve como referencial para a comparação de desempenho e para verificar a possibilidade de a unidade de produção familiar acumular. No ano agrícola estudado este índice correspondeu a 1,12, em outras palavras significa dizer que para cada unidade monetária gasta no processo produtivo tem-se um retorno de $R \$ 1,12$.

Tabela 3 - Desempenho Econômico mediano por UPF, Vale do Acre, Sistema Extrativista, Sistema Agrícola, Sistema Agroflorestal, 1996/1997 e 2005/2006, Acre Brasil.

\begin{tabular}{|c|c|c|c|c|c|c|c|c|c|}
\hline Indicadores & Unidade & $\begin{array}{c}\text { Vale do } \\
\text { Acre }\end{array}$ & $\begin{array}{c}\text { Evolução } \\
(\%)^{*}\end{array}$ & Extrativismo & $\begin{array}{c}\text { Evolução } \\
(\%)^{*}\end{array}$ & Agricultura & $\begin{array}{c}\text { Evolução } \\
(\%)^{*}\end{array}$ & Agrofloresta & $\begin{array}{c}\text { Evolução } \\
(\%)^{*}\end{array}$ \\
\hline RB & $\mathrm{R} \$ / \mathrm{mês}$ & 709,02 & 15,53 & 492,19 & 47,96 & 780,35 & $-44,86$ & $1.169,87$ & 205,80 \\
\hline RBT & $\mathrm{R} \$ / \mathrm{mês}$ & 950,43 & 49,21 & 633,62 & 81,14 & $1.077,15$ & $-25,98$ & $1.204,61$ & 154,05 \\
\hline$R L$ & $\mathrm{R} \$ / \mathrm{mês}$ & 343,66 & $-33,43$ & 246,68 & 18,80 & 343,66 & $-74,86$ & 889,35 & 197,37 \\
\hline MBF & $\mathrm{R} \$ / \mathrm{mês}$ & 564,67 & 6,66 & 450,45 & 64,81 & 580,00 & $-45,74$ & $1.046,04$ & 191,83 \\
\hline CF & $\mathrm{R} \$ / \mathrm{mês}$ & 602,47 & 223,09 & 436,62 & 308,27 & 647,06 & 170,23 & 633,33 & 695,77 \\
\hline CV & $\mathrm{R} \$ / \mathrm{mês}$ & 201,37 & 22,69 & 143,21 & 25,68 & 258,46 & 14,78 & 295,21 & 184,60 \\
\hline VBCC & $\mathrm{R} \$ / \mathrm{mês}$ & 738,04 & 159,60 & 598,94 & 277,54 & 811,65 & 132,61 & 691,76 & 92,39 \\
\hline LDM & $\mathrm{R} \$ /$ mês & $1.360,65$ & 176,57 & $1.080,50$ & 274,49 & $1.500,60$ & 137,27 & $1.253,67$ & 154,06 \\
\hline $\mathrm{AC}$ & $\mathrm{R} \$ / \mathrm{mês}$ & 240,89 & $-87,18$ & 323,57 & - 82,91 & 201,17 & - 94,31 & 394,88 & 24,11 \\
\hline NV & $\mathrm{R} \$ / \mathrm{mês}$ & 884,44 & $-54,19$ & 843,22 & $-48,11$ & 829,65 & $-68,93$ & $1.520,09$ & 149,53 \\
\hline IEE & und. & 0,73 & $-56,65$ & 0,7 & $-48,3$ & 0,74 & $-61,32$ & 1,12 & $-39,59$ \\
\hline MBF/RB & und. & 0,88 & $-1,99$ & 0,93 & 2,48 & 0,85 & $-3,93$ & 0,9 & $-3,21$ \\
\hline MBF/Qh/d & $\mathrm{R} \$ / \mathrm{dia}$ & 53,13 & 10,66 & 41,65 & 202,67 & 66,54 & $-29,46$ & 74,21 & 72,71 \\
\hline TI & und. & 0,76 & 84,14 & 0,96 & 93,54 & 0,74 & 132,83 & 0,49 & $-32,13$ \\
\hline
\end{tabular}

Obs.: Resultados medianos por UPF; * Relativo ao período 1996/1997; RB - Renda Bruta; RL Renda Líquida; MBF - Margem Bruta Familiar; CF - custo Fixo; CV - Custo Variável; BCC - Bens e Serviços Comprados no Mercado; LDM - Linha de Reprodução Familiar; AC - Aucoconsumo; 
NV - Nível de Vida em termos monetários; IEE - Índice de Eficiência Econômica; MBF/Qh/d Remuneração diária da força de trabalho familiar; TI - Termos de Intercâmbio.

Fonte: ASPF (2014).

O valor monetário que as famílias se apropriaram, evidenciado pelo nível de vida (NV) foi de $R \$ 1.520,09 /$ mês. Isto significa que as famílias residentes no RECA ganham cerca de 2,25 salários mínimos mensais, vigente em 2011, evidenciando a possibilidade de reprodução social no meio rural, em particular pela capacidade de satisfazer as necessidades de consumo tanto no mercado quanto internamente.

O Termo de Intercâmbio ( $\mathrm{TI}$ ) das unidades de produção correspondeu a 0,49 , o que significa que $49 \%$ da renda bruta gerada é consumida no processo de circulação, mediante a aquisição de bens de consumo e serviços no mercado. Evidenciando, a baixa dependência do mercado.

Nesse sentido, chama à atenção a evolução da produção para 0 autoconsumo, que cresceu 19,49\% em relação a 1996. Isso demonstra que mesmo com o aumento da renda, os agricultores continuam produzindo para sua reprodução social, demonstrando sua racionalidade quanto à não dependência total do mercado para seu sustento.

De modo geral, se percebe uma melhora no desempenho econômico dos produtores do projeto RECA, visto que os indicadores econômicos apresentam crescimento no período estudado. Isso demonstra a consolidação do SAFs do RECA, com a agroindustrialização dos produtos, como também, pela forte base do associativismo.

\subsection{A Distribuição de Renda no RECA}

Os indicadores de desempenho econômico da produção familiar do RECA analisado em seu conjunto mostram um crescimento econômico das famílias considerável em relação a 1996. Nesse estudo, o RECA é representado pelo sistema agroflorestal.

Contudo, mesmo com uma alta concentração de renda na região, notase no projeto RECA uma redução da desigualdade de renda em torno de $17 \%$ para um período em torno de uma década. Ademais, observa-se a efetividade dessa mudança na diferença entre os $10 \%$ mais "ricos" e os $50 \%$ mais "pobres" do RECA, uma vez que a queda da desigualdade beneficiou a população mais pobre na proporção de 37,31\%, conforme Tabela 4.

Também é possível verificar que os $10 \%$ mais ricos também diminuíram sua evolução e os 50\% mais pobres diminuíram em torno de 1,49\%. Esses dados demonstram uma distribuição de renda mais equitativa no Sistema de Produção Agroflorestal, em relação aos demais sistemas produtivos estudados. Isso pode ser explicado pelas regras de vida associativa existente no referido projeto, com os trabalhos comunitários e pela busca pela melhoria de vida de todos os associados. Mesmo com essa diminuição no número de pobres ainda se verifica uma alta concentração de renda, representado pelo Índice de Gini no valor de 0,42 .

Tabela 4 - Indicadores de desigualdade de renda, Vale do Acre, Sistema Extrativista, Sistema Agrícola, Sistema Agroflorestal, 1996/1997 e 2005/2006, Acre - Brasil.

Revista de Estudos Sociais | Ano 2017, N. 39, V. 20, Pag. 14 


\begin{tabular}{|c|c|c|c|c|c|c|c|c|}
\hline \multirow[b]{2}{*}{ Descrição } & \multicolumn{2}{|c|}{ Vale do Acre } & \multicolumn{2}{|c|}{ Extrativismo } & \multicolumn{2}{|c|}{ Agricultura } & \multicolumn{2}{|c|}{ Agrofloresta } \\
\hline & $2005 / 2006$ & $\begin{array}{c}\text { Evolução* } \\
(\%)\end{array}$ & $2005 / 2006$ & $\begin{array}{c}\text { Evolução* } \\
(\%)\end{array}$ & $2005 / 2006$ & $\begin{array}{c}\text { Evolução* } \\
(\%)\end{array}$ & $2005 / 2006$ & $\begin{array}{c}\text { Evolução* } \\
(\%)\end{array}$ \\
\hline Índice de Gini & 0,51 & $-14,42$ & 0,44 & $-10,18$ & 0,51 & $-5,94$ & 0,42 & $-17,02$ \\
\hline$\%$ renda $10+$ & $34 \%$ & 48,82 & $23 \%$ & $-0,76$ & $26 \%$ & 36,51 & $21 \%$ & $-38,25$ \\
\hline $\begin{array}{l}\% \text { renda } 50- \\
10 \% \text { rico / }\end{array}$ & $27 \%$ & 74,56 & $32 \%$ & 33,05 & $33 \%$ & 111,81 & $27 \%$ & $-1,49$ \\
\hline $50 \%$ pobre & 1,24 & $-14,74$ & 0,72 & $-25,42$ & 0,77 & $-35,55$ & 0,78 & $-37,31$ \\
\hline
\end{tabular}

Obs: *Em relação ao período de 1996/1997

Fonte: ASPF (2014).

A Tabela 5 apresenta uma estratificação das famílias do Vale do Acre de acordo com nível de vida (NV), em termos monetários, em relação ao Salário Mínimo vigente no país ${ }^{12}$, buscando identificar as modificações acima e abaixo da linha de pobreza ${ }^{13}$. Assim, destaca-se que o número de pobres (estrato D) e indigentes (estrato E) cresceu em níveis preocupantes tanto na agricultura quanto no extrativismo - cujo sistema não apresentava nenhum pobre ou indigente, no período de 1996/1997 -, contrastando fortemente com o sistema agroflorestal, no qual o número de pobres diminuiu em mais da metade.

Tabela 5 - Percentual de famílias por estrato de Nível de Vida (NV), em termos monetários, Vale do Acre, Sistema Extrativista, Sistema Agrícola, Sistema Agroflorestal, 1996/1997 e 2005/2006, Acre - Brasil. (em \%)

\begin{tabular}{lcccccccc}
\hline \multirow{2}{*}{ Estratos } & \multicolumn{2}{c}{ Geral } & \multicolumn{2}{c}{ Extrativismo } & \multicolumn{2}{c}{ Agricultura } & \multicolumn{2}{c}{ Agrofloresta } \\
\cline { 2 - 9 } & $2005 / 2006$ & Evolução* & $2005 / 2006$ & Evolução* & $2005 / 2006$ & Evolução* & $2005 / 2006$ & Evolução* \\
\hline A & 9 & -74 & 3 & -87 & 12 & -73 & 20 & 480 \\
B & 18 & -35 & 23 & -36 & 15 & -42 & 43 & 151 \\
C (a) & 39 & 812 & 42 & 3185 & 38 & 839 & 20 & 45 \\
C (b) & 21 & -38 & 22 & -46 & 20 & -23 & 10 & -83 \\
D & 10 & 577 & 9 & 8811 & 10 & 770 & 3 & -52 \\
E & 5 & 552 & 2 & 1880 & 6 & 432 & 3 & 3233 \\
\hline
\end{tabular}

Obs: * Em relação ao período 1996/1997

Fonte: ASPF (2014).

Isso demonstra que mesmo existindo concentração de renda, o sistema produtivo praticado pelos produtores familiares do projeto RECA ainda consegue distribuir a renda de forma mais equitativa. Talvez isso seja justificado através do histórico da associação e a busca pela melhoria da qualidade de vida para todos, com respeito ao meio ambiente. Isso também corrobora o pensamento de Sachs (1991): "[...] os problemas da pobreza e do meio ambiente podem ser sanados ou evitados; não há quaisquer limites ecológicos ou falta de tecnologia que impeçam sua superação. Conclui-se que os obstáculos são sociais e políticos".

\footnotetext{
$12 \mathrm{R} \$ 724,00 / \mathrm{mês}$

${ }^{13}$ Conforme o IBGE (2008), no Brasil, a metodologia oficial usa como referência o salário mínimo mensal para delimitar a linha de pobreza, sendo considerada "pobre" aquela família que tem renda familiar per capita abaixo de 1/2 do salário mínimo e "indigente" aquela família que tem renda familiar per capita abaixo de 1/4 do salário mínimo.
}

Revista de Estudos Sociais | Ano 2017, N. 39, V. 20, Pag. 15 


\section{CONSIDERAÇÕES FINAIS}

Este trabalho procurou, por um lado, desenvolver uma reflexão com base em dados empíricos sobre a produção familiar rural e a concentração de renda no Projeto RECA, em Rondônia, buscando compreender como a renda evoluiu e foi distribuída ao longo de dez anos. Para isso utilizou-se indicadores de desempenho econômico e de medidas de concentração de renda. Pelos dados encontrados constatou-se que ocorreu uma diminuição no número de pobres e uma distribuição de renda mais equitativa quando comparado com outros sistemas produtivos praticados na região.

De modo geral, o que se encontrou no RECA representa a diferenciação interna existente na produção familiar em uma sociedade capitalista. Tais desigualdades são geradas pelas diferentes rendas obtidas pelos produtores, quando comercializam suas colheitas. Alguns ganham mais que o dobro dos investimentos, enquanto muitos não recebem nem mesmo os valores investidos. Essa diferenciação econômica é resultado, principalmente, de fatores como pouca mão de obra familiar disponível, má gestão da propriedade, falta de assistência técnica, controle de preços, de mercados e de políticas agrícolas eficazes.

Neste sentido, os resultados econômicos obtidos pelos agricultores são essenciais para fortalecer as estratégias de desenvolvimento. Mas não se trata apenas de buscar aumento de produtividade e atendimento do mercado a qualquer custo, porque isso pode ocasionar, em longo prazo, diminuição de renda, dependência crescente de fatores externos e danos que podem se traduzir em perdas econômicas no curto prazo.

Além da melhoria dos sistemas produtivos que se fazem necessários, se não houver maior envolvimento dos jovens nas atividades produtivas e da associação a continuidade da mesma estará comprometida, visto o grande número de idosos e crianças encontrados e até o momento não se identifica algo na ação do RECA que leve a juventude a se interessar pelos ideais da vida associativa como se percebe nos seus pais. $O$ grande diferencial para 0 desenvolvimento do RECA será a efetiva participação dos jovens e crianças e uma maior diversificação dos sistemas produtivos.

A estratégia de redução da pobreza solicita o crescimento da renda per capita ou a distribuição mais igualitária da renda. Uma combinação de políticas que estimulem o crescimento econômico e diminuam a desigualdade, em princípio, aparenta conceder maior eficácia e velocidade ao processo de combate à pobreza. Nesse sentido, são essenciais políticas que incentivem o cooperativismo, melhorias de preços agrícolas, assistência técnica e extensão rural que respeite e potencialize as aptidões da região, educação, saúde, cultura e lazer, dentre outras para acelerar o processo de redução da pobreza. Ou seja, um conjunto de políticas que no dizer de Diegues (1992), "reúna um conjunto de preocupações sobre as relações entre o homem, e a natureza e também dos homens entre si".

\section{REFERÊNCIAS BIBLIOGRÁFICAS}

Revista de Estudos Sociais | Ano 2017, N. 39, V. 20, Pag. 16 
ASPF - Análise Socioeconômica de Sistemas Básicos de Produção Familiar Rural no Estado Acre. 2014. Disponível em: http://aspf.wordpress.com/. (Centro de Ciências Jurídicas e Sociais Aplicadas UFAC).

CAMPOS, Robério Telmo; CAMPOS, Kilmer Coelho. Análise das medidas de renda, distribuição e pobreza dos municípios da área de influencia da barragem Castanhão- Ceará. In: Congresso Brasileiro de Economia, Administração e Sociologia Rural, 46ํㅡ, 2008, Rio Branco. Anais...Rio Branco: SOBER, 2010. (1 CD-ROM).

DIEGUES, Antonio Carlos S. Desenvolvimento Sustentável ou sociedades sustentáveis: da crítica dos modelos aos novos paradigmas. São Paulo em Perspectiva, v. 6, 1992.

FRANKE, I. L. A Aprendizagem tecnológica e organizacional na perfomance do sistema produtivo e institucional do Reca. 197p., $297 \mathrm{~mm}$, (UnB, Mestre, Política e Gestão de C \& T, 2005).

GUDYNAS, Eduardo. Ecologia, economia y ética del desarollo sostenible. Revista de Ecologia Política de Bolívia. 02 ICIB/ANCB. Uruguai, 2003.

LOIOLA, T. O.; MACIEL, R. C G. Segurança Alimentar, Produção Rural e Desigualdade de Renda na Amazônia: Um Estudo de Caso no Projeto de Desenvolvimento Sustentável Bonal - Acre - Brasil. Revista Faz Ciência, Toledo, 2015. vol. 17, n. 26, jul/dez - p. 30-49.

MACIEL, R. C. G. et. al. Distribuição de Renda e Pobreza na Floresta Amazônica: Um Estudo a partir da Reserva Extrativista (RESEX) Chico Mendes. Revista de Estudos Sociais. Cuiabá, 2014. N. 32 Vol 16, p. 136-153.

MACIEL, Raimundo Claúdio Gomes (Org.) Diagnóstico Socioecônomico dos sistemas básicos de produção familiar rural do estado do Acre (ASPF). Período 1996/2006. Rio Branco: EDUFAC, 2011. 150p.

NOSSO FUTURO COMUM. Comissão Mundial sobre Meio Ambiente e Desenvolvimento. Rio de Janeiro: ed. da Fundação Getúlio Vargas, 1991.

RECA. Nosso jeito de caminhar: a História do Reca contada por seus associados, parceiros e amigos. Brasília, 2003. 143p.

RÊGO, J. F. do. Análise econômica dos sistemas de produção familiar rural do vale do Acre 1996/1997. Rio Branco UFAC; SEBRAE, The Ford Fundation, 2003, 80p.il.

ROCHA, S. Opções metodológicas para a estimação de linhas de indigência e de pobreza no Brasil. Ipea, Rio de Janeiro, abr. de 2000b, (Texto para Discussão, n.720). 
SCHNEIDER, Sérgio, FIALHO, Marco Antonio Verard. Pobreza Rural, desequilíbrios regionais e desenvolvimento agrário no Rio Grande do Sul. Teoria. Evid. Econômico. Passo Fundo, V. 08. N. 15, p. 117-150. 2000.

SILVA, C. L. da, MENDES, J. T. G (orgs). Reflexões sobre o desenvolvimento sustentável: agentes e interações sobre a ótica da multidisciplinar. Petrópolis, RJ: Vozes: 2005.

SILVA, N. M.; LOPES, C. M. D'A.; NERY, D.S 2007. Manejo integrado da broca do fruto do cupuaçuzeiro. Cartilha de Difusão INPA/UFAM/PPD/PPG-7, Manaus, 15p.

SOUZA, Elyson Ferreira de. Os Pólos Agroflorestais como Política de Desenvolvimento Rural Sustentável em Rio Branco no Acre: da proposição à realidade. Viçosa: DED/UFV, 2008. 180 p. (Dissertação de Mestrado Economia Doméstica, DED/UFV). 